\title{
Graphite-Furnace Atomic Absorption Spectrometry of Organomercury and Organoselenium in Extracts of Biological Samples with an Organopalladium Matrix Modifier
}

\author{
Hui Li*, Hiromichi Nagasawa** and Kazuko Matsumoto* \\ * Department of Chemistry, Waseda University, Okubo, Tokyo 169, Japan \\ ** Ocean Research Institute, The University of Tokyo, Minamidai, Nakano, Tokyo 164, Japan
}

\begin{abstract}
The sensitivity of organomercury in organic solutions has been found to be enhanced by applying $15 \mu$ of an ethanol solution of $\mathrm{Pd}(\mathrm{acac})_{2}\left(500 \mu \mathrm{gPd} \mathrm{m} l^{-1}\right.$, acac is acetylacetonate) to a graphite-furnace, which is then heated to make a Pd coating on the furnace. After this treatment, an ethanol solution of the sample is injected to the furnace and measured. With this method, the detection limit of organomercury was found to be $0.25 \mathrm{ng}$. In a slightly different way, in which $2 \mathrm{ml}$ of an ethanol solution of $\mathrm{PdCl}_{2}(\mathrm{PhCN})_{2}\left(1000 \mu \mathrm{gPd} \mathrm{ml}^{-1}\right)$ was added as a matrix modifier to $3 \mathrm{ml}$ of an ethanol solution of organoselenium, selenium was determined with a detection limit of $0.12 \mathrm{ng}$. These methods can be successfully applied to the determinations of organomercury and organoselenium in an extract solution of a dolphin liver.
\end{abstract}

Keywords Organomercury, organoselenium, matrix modifier, palladium, organic solvent

Mercury gives only very poor sensitivity in conventional graphite-furnace atomic absorption spectrometry, and is therefore usually measured by cold-vapor atomic absorption spectrometry (CVAAS) to achieve a high sensitivity for practical purposes. ${ }^{1-6}$ The detection limit

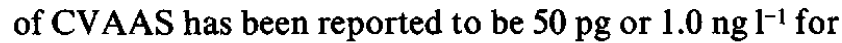
environmental samples. ${ }^{4}$ The use of matrix modifiers has remarkably enhanced the capability of conventional graphite-furnace atomic absorption spectrometry (GFAAS) for volatile elements in real samples. For instance, $\mathrm{K}_{2} \mathrm{Cr}_{2} \mathrm{O}_{7},{ }^{7} \mathrm{Na}_{2} \mathrm{O},{ }^{7}$ sulfate salt, ${ }^{8}$ and a combination of $\mathrm{HCl}-\mathrm{H}_{2} \mathrm{O}_{2}{ }^{9}$ have been reported as matrix modifiers for inorganic mercury measurements. Ni and Shan reported, after a comparative experiment regarding the effect of gold, platinum and palladium, that the ashing temperature of mercury can be raised to $500^{\circ} \mathrm{C}$ by the addition of $400 \mathrm{ng}$ of palladium; a detection limit of $0.2 \mathrm{ng} \mathrm{Hg}$ was obtained. ${ }^{10}$ Weltz et al. have reported on a different palladium modification method for mercury, in which a graphite furnace is first coated with palladium by applying a $\mathrm{Pd}$ solution to the furnace and heating it before a mercury solution is applied to the furnace. ${ }^{11}$

Similarly to the case of mercury, vaporization loss causes a low sensitivity in selenium determination. For selenium measurements, nickel, magnesium, and palladium, or their combinations ${ }^{12-19}\left(\mathrm{CdCl}_{2}-\mathrm{PdCl}_{2}{ }^{20}\right.$ and $\mathrm{HgCl}_{2}-\mathrm{PdCl}_{2}{ }^{21}$ ) have been reported as modifiers. A detection limit of $28 \mathrm{pg}$ Se has been reported with nickel being used as the matrix modifier and with a polarized Zeeman correction. ${ }^{15}$ Larsen and Ekelund reported that the relative standard deviation was improved to $4.2 \%$ by using $\mathrm{Mg}\left(\mathrm{NO}_{3}\right)_{2}-\mathrm{Pd}\left(\mathrm{NO}_{3}\right)_{2}$ in the determination of $\mathrm{Se}$ in a cultivated yeast standard reference material. ${ }^{19}$
In the present study, organopalladium compounds were examined as possible matrix modifiers for organomercury and organoselenium in organic solvents. Such matrix modification in an organic solvent has not been attempted for organomercury and organoselenium compounds, and seems to be promising and indispensable for characterization and speciation studies of the two elements in biological samples.

\section{Experimental}

\section{Apparatus and measurement}

A Hitachi Z-9000 atomic absorption spectrometer with a Zeemen background correction was used. Pyrolyzed graphite tubes were used for the measurements. Mercury and selenium atomic lines of 253.6 and $196.0 \mathrm{~nm}$ were used, respectively, and $20 \mu$ of a solution was used for the measurements. The heating program for the two elements were as follows-Hg: dry, $50-120^{\circ} \mathrm{C}$ for $60 \mathrm{~s}$, $150^{\circ} \mathrm{C}$ for $20 \mathrm{~s}$; ash, $350^{\circ} \mathrm{C}$ for $20 \mathrm{~s}$; atomization, $1000^{\circ} \mathrm{C}$ for $5 \mathrm{~s}$; and cleaning at $1500^{\circ} \mathrm{C}$ for $5 \mathrm{~s}$; Se: dry, $80-120^{\circ} \mathrm{C}$ for $30 \mathrm{~s}, 120-200^{\circ} \mathrm{C}$ for $20 \mathrm{~s}$; ash, variable for $30 \mathrm{~s}$; atomization, $2400^{\circ} \mathrm{C}$ for $7 \mathrm{~s}$; and cleaning at $2650^{\circ} \mathrm{C}$ for $3 \mathrm{~s}$.

For a mercury measurement, $15 \mu \mathrm{l}$ of a $500 \mu \mathrm{gPd} \mathrm{ml}^{-1}$ ethanol solution of $\operatorname{Pd}(\mathrm{acac})_{2}$ (acac is acetylacetonate) was injected three times to the graphite furnace before the heating cycle was started. The furnace was heated with the program described above to make a Pd coating on the furnace. After this procedure, $20 \mu \mathrm{I}$ of a sample solution was injected and then measured.

For a selenium measurement, $2.0 \mathrm{ml}$ of a $1000 \mu \mathrm{gPd}$ 
$\mathrm{ml}^{-1}$ ethanol solution of $\mathrm{PdCl}_{2}(\mathrm{PhCN})_{2}$ was mixed with $3.0 \mathrm{ml}$ of a sample solution; $20 \mu \mathrm{l}$ of the mixed solution was injected for the measurement.

\section{Extraction of Se and $\mathrm{Hg}$ from a dolphin liver}

Part of a frozen dolphin liver was cut into small pieces with a knife, and extracted with acetone and ethanol, as the procedure described in Fig. 1 shows. The acetone and ethanol solutions were subjected to $\mathrm{Hg}$ and $\mathrm{Se}$ analyses. The heating conditions of GFAAS were those described above, except that the ashing temperature for Se was $1400^{\circ} \mathrm{C}$ for $30 \mathrm{~s}$.

\section{Reagents}

The standard solutions of organopalladium compounds $\mathrm{PdCl}_{2}\left(\mathrm{CH}_{3} \mathrm{CN}\right)_{2}, \mathrm{Pd}(\mathrm{acac})_{2}, \mathrm{PdCl}_{2}(\mathrm{PhCN})_{2}$ were prepared by first dissolving each reagent-grade compound in a small amount of acetone, which was then diluted to $1000 \mu \mathrm{gPd} \mathrm{ml}^{-1}$ with ethanol. For organomercury and organoselenium standard solutions, methylmercury chloride and selenourea were dissolved, respectively in ethanol to $1000 \mu \mathrm{g} \mathrm{ml}^{-1}$, and were used as standard solutions.

\section{Results and Discussion}

Dependence of the mercury sensitivity on the ashing temperature and chemical forms of palladium

Without a Pd modifier the ashing temperature for a mercury measurement can be raised only to around $100^{\circ} \mathrm{C}$, because volatilization loss of mercury occurs very easily even at low temperatures. We have already reported that the addition of $\mathrm{Pd}\left(\mathrm{NO}_{3}\right)_{2}$ to inorganic mercury in an aqueous solution enables an ashing temperature as high as $450^{\circ} \mathrm{C}$ without any appreciable volatilization loss. ${ }^{22}$ No attempt has been reported for an organomercury determination with palladium addition in organic solvents. We have reported that organopalladium can be used effectively for organotin in organonic solvents, just as inorganic palladium is widely used as a matrix modifier in aqueous solutions for various inorganic elements. ${ }^{24-26}$ Organomercury is more volatile than inorganic mercury; it is of interest to examine whether organopalladium acts effectively to organomercury in organic solvents similarly to organotin. Our experiment shows, as in Fig. 2, that by coating the graphite furnace with $\mathrm{Pd}$, the ashing temperature can be raised to $350^{\circ} \mathrm{C}$, whereas without a Pd treatment the sensitivity rapidly decreases with the ashing temperature being raised to higher than $150^{\circ} \mathrm{C}$. The sensitivity decreased to half when the $\mathrm{Hg}$ and $\mathrm{Pd}$ solutions were mixed, and the mixture was applied to the furnace. Once the Pd treatment was applied to the furnace, the surface of the furnace became stable and durable for about $40 \mathrm{Hg}$ measurements without any appreciable sensitivity loss. Figure 2 also shows that the chemical form of the Pd compound does not affect the sensitivity, which is distinctly different from an

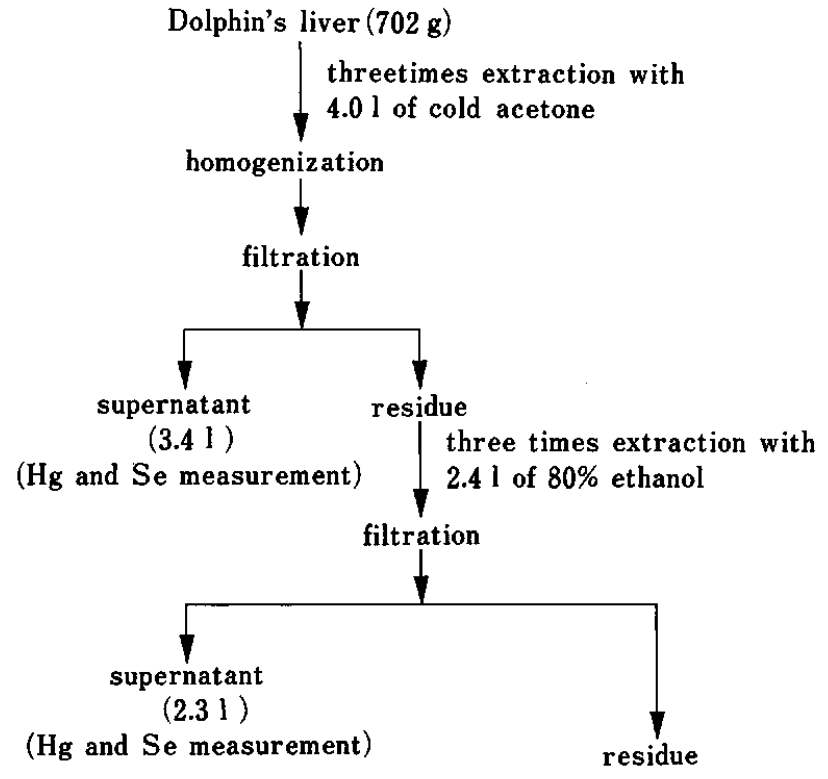

Fig. 1 Extraction procedure for the determination of Se and $\mathrm{Hg}$ in dolphin livers.

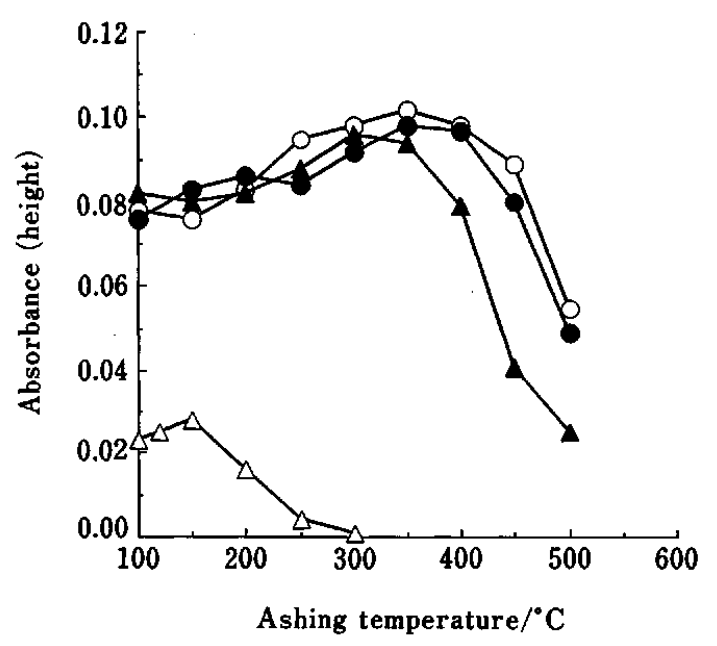

Fig. 2 Effect of the ashing temperature on the $\mathrm{Hg}$ sensitivity when several organopalladium compounds are added as matrix modifiers. $\mathrm{OPd}(\mathrm{acac})_{2}, \mathrm{Hg} 1.0 \mu \mathrm{g} \mathrm{ml}^{-1}$; - $\mathrm{PdCl}_{2}\left(\mathrm{CH}_{3} \mathrm{CN}\right)_{2}, \mathrm{Hg} 1.0 \mu \mathrm{g} \mathrm{ml}^{-1} ; \Delta \mathrm{PdCl}_{2}(\mathrm{PhCN})_{2}, \mathrm{Hg}$ $1.0 \mu \mathrm{g} \mathrm{ml}^{-1} ; \triangle$ without Pd, Hg $1.0 \mu \mathrm{g} \mathrm{ml}^{-1}$.

organotin measurement with organo Pd modifiers; in the latter case, Pd organic solutions are mixed before a measurement, and the mixed solution is applied to the measurement. The tin sensitivity and highest applicable ashing temperature differ significantly, depending on the palladium compound. ${ }^{24}$ In the following analysis of extract solutions, $\operatorname{Pd}(\mathrm{acac})_{2}$ was used. The best ashing temperature, enhancement ratio, and the detection limit are summarized in Table 1 . The detection limit of the present study (3r) is comparable to that of inorganic 
Table 1 Enhancement ratios and detection limits of organomercury with several organopalladium matrix modifiers

\begin{tabular}{lccc}
\hline \multicolumn{1}{c}{$\begin{array}{c}\text { Matrix } \\
\text { modifier }\end{array}$} & $\begin{array}{c}\text { Optimum } \\
\text { ashing } \\
\text { temp. } /{ }^{\circ} \mathrm{C}\end{array}$ & $\begin{array}{c}\text { Enhancement } \\
\text { ratio }\end{array}$ & $\begin{array}{c}\text { Detection } \\
\text { limit } / \mathrm{ng}\end{array}$ \\
\hline $\mathrm{PdCl}_{2}\left(\mathrm{CH}_{3} \mathrm{CN}\right)_{2}$ & 350 & 340 & 0.29 \\
$\mathrm{Pd}_{(\mathrm{acac})_{2}}$ & 350 & 340 & 0.25 \\
$\mathrm{PdCl}_{2}(\mathrm{PhCN})_{2}$ & 300 & 300 & 0.27 \\
None & 150 & 1.0 & - \\
\hline
\end{tabular}

mercury in an aqueous solution with an inorganic $\mathbf{P d}$ modifier. ${ }^{10}$

Dependence of the selenium sensitivity on the ashing temperature and chemical form of palladium

The effect of the ashing temperature on the selenium sensitivity is shown in Fig. 3 for several organopalladium modifiers. $\mathrm{PdCl}_{2}(\mathrm{PhCN})_{2}$ gave the highest possible ashing temperature of $1400^{\circ} \mathrm{C}$ with the highest sensitivity. Therefore, $\mathrm{PdCl}_{2}(\mathrm{PhCN})_{2}$ was used in the following experiment. With $\mathrm{PdCl}_{2}\left(\mathrm{CH}_{3} \mathrm{CN}\right)_{2}$, the Se sensitivity decreased and volatilization loss was observed above $700^{\circ} \mathrm{C}$. The enhancement ratio and the detection limit are summarized in Table 2. Although each organopalladium compound exhibits different optimum conditions, but the enhancement ratios and detection limits are not very much different from each other. The detection limits $(3 \sigma)$ obtained in the present method are almost comparable to that of inorganic selenium in an aqueous solution with a $\mathrm{HgCl}_{2}-\mathrm{PdCl}_{2}$ modifier. ${ }^{21}$ Since

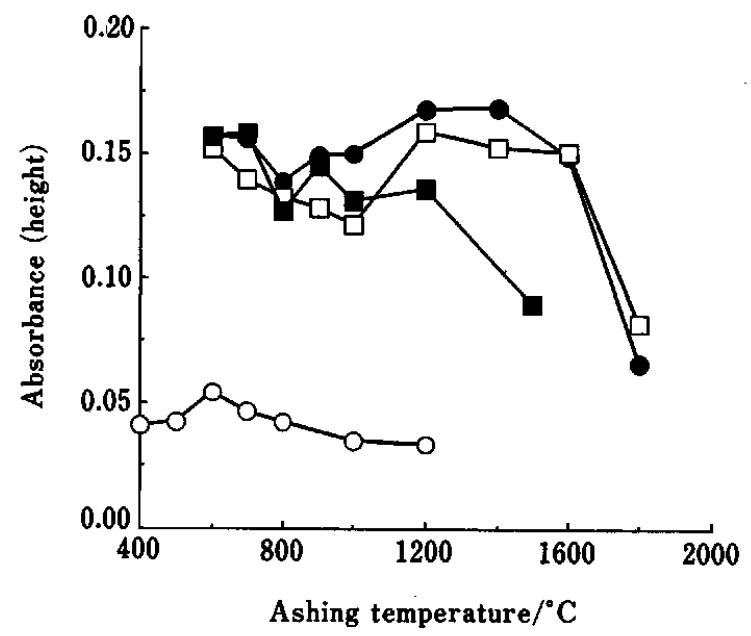

Fig. 3 Effect of the ashing temperature on the Se sensitivity when several organopalladium compounds are added as matrix modifiers. $\square \mathrm{Pd}(\text { acac })_{2}, 400 \mu \mathrm{gPd} \mathrm{ml}^{-1}$; $\mathrm{PdCl}_{2}(\mathrm{PhCN})_{2}, \quad 200 \mu \mathrm{gPd} \mathrm{ml}{ }^{-1} ; \quad \mathrm{PdCl}_{2}\left(\mathrm{CH}_{3} \mathrm{CN}\right)_{2}$, $5.0 \mu \mathrm{gPd} \mathrm{ml}^{-1}$; O without Pd. A solution of $0.15 \mathrm{mgSe} \mathrm{ml}^{-1}$ was used throughout the measurement. The above concentrations for the $\mathrm{Pd}$ compounds were optimized in a preliminary experiment.

$\mathrm{PdCl}_{2}(\mathrm{PhCN})_{2}$ allows the highest ashing temperature, the following Se determination was carried out with $\mathrm{PdCl}_{2}(\mathrm{PhCN})_{2}$.

Analysis of mercury and selenium in the extract solutions of a dolphin liver

The above-described methods for organomercury and

Table 2 Enhancement ratios and detection limits of organoselenium with several organopalladium matrix modifiers

\begin{tabular}{lcccc}
\hline Matrix modifier & Optimum conc. $/ \mu \mathrm{g} \mathrm{ml}^{-1}$ & Optimum ashing temp. $/{ }^{\circ} \mathrm{C}$ & Enhancement ratio & Detection limit $/ \mathrm{ng}$ \\
\hline $\mathrm{PdCl}_{2}(\mathrm{PhCN})_{2}$ & 200 & 1400 & 2.8 & 0.12 \\
$\mathrm{Pd}_{2}(\mathrm{acac})_{2}$ & 400 & 1200 & 3.0 & 0.14 \\
$\mathrm{PdCl}_{2}\left(\mathrm{CH}_{3} \mathrm{CN}\right)_{2}$ & 5.0 & 700 & 2.8 & 0.08 \\
None & 0 & 600 & 1.0 & - \\
\hline
\end{tabular}

Table 3 Determination of $\mathrm{Hg}$ and $\mathrm{Se}$ in acetone and ethanol extract solutions of a dolphin liver

\begin{tabular}{|c|c|c|c|c|c|}
\hline \multirow{2}{*}{ Analyte } & \multirow{2}{*}{ Added amount $/ \mu \mathrm{g} \mathrm{ml}^{-1}$} & \multicolumn{2}{|l|}{ Acetone } & \multicolumn{2}{|l|}{ Ethanol } \\
\hline & & Concentration $^{\mathrm{a}} / \mu \mathrm{g} \mathrm{ml}^{-1}$ & Recovery, \% & Concentration ${ }^{a} / \mu \mathrm{g} \mathrm{ml}^{-1}$ & Recovery, \% \\
\hline \multirow[t]{4}{*}{$\mathrm{Hg}$} & 0 & $0.68 \pm 0.08$ & - & $2.06 \pm 0.14$ & - \\
\hline & 0.20 & $0.71 \pm 0.06$ & 80.7 & $2.03 \pm 0.12$ & 89.8 \\
\hline & 0.40 & $0.89 \pm 0.03$ & 82.4 & $2.26 \pm 0.15$ & 91.9 \\
\hline & 0.80 & $1.29 \pm 0.08$ & 87.2 & $2.69 \pm 0.10$ & 94.1 \\
\hline \multirow[t]{4}{*}{$\mathrm{Se}$} & 0 & $0.23 \pm 0.02$ & - & $0.89 \pm 0.07$ & - \\
\hline & 0.02 & $0.22 \pm 0.01$ & 88.0 & $0.85 \pm 0.06$ & 93.4 \\
\hline & 0.05 & $0.26 \pm 0.05$ & 92.8 & $0.84 \pm 0.04$ & 89.4 \\
\hline & 0.12 & $0.33 \pm 0.03$ & 94.3 & $0.99 \pm 0.06$ & 97.0 \\
\hline
\end{tabular}

a. $X \pm \sigma$ ( $\sigma$ was determined with five-time measurements). 
Table 4 Analytical results ( $\mu \mathrm{g} \mathrm{ml}^{-1}$ ) of mercury and selenium in extract solutions of dolphin livers

\begin{tabular}{cccccc}
\hline \multirow{2}{*}{$\begin{array}{c}\text { Sample } \\
\text { No. }\end{array}$} & \multicolumn{2}{c}{ Acetone $^{\mathrm{a}}$} & & \multicolumn{2}{c}{ Ethanol $^{\mathrm{a}}$} \\
\cline { 2 - 3 } \cline { 5 - 6 } & $\mathrm{Hg}$ & $\mathrm{Se}$ & $\mathrm{Hg}$ & $\mathrm{Se}$ \\
\hline 1 & $0.68 \pm 0.08$ & $0.23 \pm 0.02$ & & $2.06 \pm 0.14$ & $0.89 \pm 0.07$ \\
2 & $0.46 \pm 0.05$ & $0.15 \pm 0.03$ & & $1.87 \pm 0.10$ & $0.56 \pm 0.03$ \\
3 & $0.36 \pm 0.06$ & $0.12 \pm 0.05$ & & $0.43 \pm 0.07$ & $0.15 \pm 0.01$ \\
4 & $0.40 \pm 0.05$ & $0.12 \pm 0.01$ & & $0.46 \pm 0.04$ & $0.18 \pm 0.02$ \\
5 & $0.38 \pm 0.07$ & $0.16 \pm 0.02$ & & $0.42 \pm 0.04$ & $0.14 \pm 0.04$ \\
\hline
\end{tabular}

a. $X \pm \sigma$ ( $\sigma$ was determined with five-time measurements).

organoselenium determinations were applied to the analysis of acetone and ethanol extract solutions of a dolphin liver. Table 3 shows the analytical results obtained with a standard addition method. The $\mathbf{H g}$ recovery is better for ethanol solutions than acetone. The recovery of $\mathrm{Hg}$ is generally poorer than that of Se. Table 4 is the analytical results for the extract solutions of other dolphin livers. These results show that the present method is applicable to real samples.

\section{References}

1. N. S. Poluéktov, R. V. Vitkum and Y. Z. Zelyukova, Zh. Anal. Khim., 19, 937 (1964).

2. W. R. Hatch and W. L. Ott, Anal. Chem., 40, 2085 (1968).

3. G. Topping and J. M. Pirie, Anal. Chim. Acta, 62, 200 (1972).

4. B. Welz and M. Melcher, At. Spectrosc., 5, 37 (1984).

5. W. Baeyens and M. Leermakers, J. Anal. At. Spectrom., 4, 635 (1989)

6. G. A. Zachariodis and J. A. Stratis, J. Anal. At. Spectrom., 6, 239 (1991).
7. G. F. Kirkbright, X. Q. Shan and R. D. Snook, At. Spectrosc., 1, 85 (1980).

8. R. D. Ediger, At. Absorpt. Newsl., 14, 127 (1975).

9. J. F. Alder and D. A. Hickman, Anal. Chem., 49, 336 (1977).

10. Z. M. Ni and X. Q. Shan, Spectrochim. Acta, 42B, 937 (1987).

11. B. Welz, G. Schlemmer and J. R. Mudakavi, J. Anal. At. Spectrom., 7, 499 (1992).

12. R. D. Ediger, At. Absorpt. Newsl., 14, 127 (1975).

13. G. Alfthan and J. Kumpulainen, Anal. Chim. Acta, 140, 221 (1982)

14. L. J. Dillon, D. C. Hilderbrand and K. S. Groon, At. Spectrosc., 3, 5 (1982).

15. G. R. Carnrick, D. C. Manning and W. Slavin, Analyst [London], 108, 1297 (1983).

16. G. Schlemmer and B. Welz, Spectrochim. Acta, 41B, 1157 (1986).

17. B. Welz, G. Schlemmer and J. R. Mudakavi, J. Anal. At. Spectrom., 3, 93 (1988).

18. M. Bettinelli, U. Baroni and N. Pastorelli, J. Anal. At. Spectrom., 3, 1005 (1988).

19. E. H. Larsen and J. Ekelund, Analyst [London], 114, 915 (1989).

20. C. Garcia-Olalla, L. C. Robles, M. T. Alemany and A. J. Aller, Anal. Chim. Acta, 247, 19 (1991).

21. C. Garcia-Olalla and A. J. Aller, Anal. Chim. Acta, 259, 295 (1992).

22. P. Liu, K. Fuwa and K. Matsumoto, Anal. Chim. Acta, 171, 279 (1985).

23. J. E. T. Nishimura, T. Tominaga, T. Katsura and K. Matsumoto, Anal. Chem., 59, 1647 (1987).

24. T. Katsura, F. Kato and K. Matsumoto, Anal. Sci., 6, 909 (1990).

25. T. Katsura, F. Kato and K. Matsumoto, Anal. Chim. Acta, 252, 77 (1991).

26. H. Li, B. Gong, T. Ochiai and K. Matsumoto, Anal. Sci., 9, 707 (1993) 